\title{
Program Pendampingan Strategi Pemasaran Digital untuk IKM Renafa Food
}

\author{
Hetty Karunia Tunjungsari ${ }^{1 *}$, Frangky Slamet ${ }^{2}$, Bagus Mulyawan ${ }^{3}$ \\ ${ }^{123}$ Jurusan Manajemen, Universitas Tarumanagara Jakarta, Indonesia \\ Author E-mail: hetty@fe.untar.ac.id
}

\begin{abstract}
A B S T R A K
Kegiatan PKM ini dilakukan degan melibatkan mitra IKM Renafa Food yang berlokasi di Tanjung Gedong, Kecamatan Grogol Petamburan, Jakarta Barat. Kegiatan berlangsung dari bulan Juli hingga Oktober 2021 yang diawali dengan identifikasi permasalahan, analisis kebutuhan, hingga program pendampingan. Hasil identifikasi permasalahan yang dilakukan oleh tim menunjukkan bahwa IKM Renafa Food membutuhkan bantuan untuk mendesain strategi pemasaran digital dalam memasarkan produknya. Dengan demikian, tujuan kegiatan PKM ini adalah untuk menyusun strategi pemasaran digital bagi IKM Renafa Food, khususnya pemasaran di media sosial. Dalam kegiatan ini, tim PKM melakukan komunikasi intensif dengan pemilik IKM Renafa Food baik secara daring maupun luring. Hasil kegiatan ini berupa materi pemasaran digital yang dapat digunakan oleh IKM Renafa Food untuk melakukan promosi di media sosial. Secara keseluruhan, kegiatan PKM dapat berjalan dengan lancar tanpa kendala yang berarti. Manfaat dari kegiatan PKM ini secara langsung dapat dirasakan oleh IKM Renafa Food untuk membantu melengkapi materi promosi di media sosial Instagram dalam bentuk poster digital.
\end{abstract}

Kata Kunci: UMKM, Strategi, Pemasaran Digital, Pendampingan

\section{A B S T R A C T}

This community engagement activity was carried out by involving the MSME's partner, Renafa Food, which located in Tanjung Gedong, Grogol Petamburan District, West Jakarta. The activity takes place from July to October 2021, starting with problem identification, analysis of partner's needs, and mentoring programs. From the identification of the problems, team indicates that Renafa Food needs assistance in designing digital marketing strategies in marketing their products. Thus, the purpose of this community engagement activity is to develop a digital marketing strategy for Renafa Food, especially marketing on social media. In this activity, the community engagement team had intensive communication with the owners of Renafa Food both online and offline. The results of this activity are in the form of digital marketing materials that can be used by Renafa Food to promote their products on social media. Overall, these activities can run smoothly without any significant problems. 
The benefits of these activities give advantages directly to Renafa Food to equip promotional materials on Instagram in the form of digital posters.

Keywords: MSMEs, Strategy, Digital Marketing, Mentoring

Copyright (c) 2021 Authors. This is an open access article distributed under the Creative Commons Attribution License, which permits unrestricted use, distribution, and reproduction in any medium, provided the original work is properly cited.

\section{PENDAHULUAN}

Indonesia merupakan negara yang memiliki aneka ragam produk khas daerah yang telah memiliki reputasi internasional, seperti misalnya batik dari industri fesyen, rendang dari industri makanan, hingga Candi Borobudur dan Raja Ampat dari industri pariwisata. Berbagai produk ini baik yang berupa barang maupun jasa dikenal tidak hanya karena memiliki kekhasan tetapi juga karena kualitasnya pun mampu bersaing di dunia bisnis internasional. Produk yang dihasilkan pun tidak melulu berasal dari perusahaan besar yang memiliki aset miliaran rupiah, namun tidak sedikit UKM/IKM Indonesia yang memiliki produk berkualitas dan dibeli oleh konsumen secara luas baik nasional maupun internasional. Bahkan pemberdayaan usaha mikro, kecil, dan menengah (UMKM) menjadi salah satu program prioritas pemerintahan Jokowi- Ma'ruf dalam lima tahun ke depan (Siregar \& Tambun, 2019).

Di tengah gencarnya semangat UMKM dan pemerintah untuk meningkatkan kapasitas usaha secara internasional, Indonesia merupakan salah satu negara yang terdampak pandemi Covid-19 yang saat ini tengah melanda dunia. Pandemi Covid-19 telah mengubah berbagai aspek dalam kehidupan manusia secara luas dan dunia bisnis merupakan salah satu sektor yang mengalami dampak signifikan. Di Indonesia, dampak pada dunia bisnis cukup terasa sejak diberlakukan PSBB di sejumlah daerah pada bulan Maret 2020 lalu. Tidak sedikit wirausaha yang kemudian mengalihkan fokus kegiatan bisnisnya atau bahkan terpaksa menghentikan kegiatan bisnisnya karena kehilangan konsumen.
Salah satu industri yang terdampak pandemi Covid-19 adalah industri makanan, baik lokal maupun internasional, yang sebelum masa pandemi dipasarkan secara konvensional di toko fisik.

Seperti diulas pada (Hidayat \& Hidayat, 2020) pertumbuhan industri makanan dan minuman (mamin) berpeluang terhambat selama pandemi corona (Covid-19) berlangsung. Para pelaku industri berharap pemerintah dapat mendorong konsumsi di tengah masyarakat dengan menyegerakan pemberian stimulus. Survey yang dilakukan oleh BPS seperti dikemukakan oleh Direktur Statistik Kependudukan dan Ketenagakerjaan BPS Nurma Midayanti, 82,55 persen pelaku usaha yang disurvei mengalami penurunan pendapatan (Fauzia \& Erlangga, 2020). Hal ini menunjukkan pentingnya upaya menekan angka penurunan produktivitas industri untuk menghindari kemerosotan perekonomian sebagai akibat hilangnya pendapatan usaha.

Sebagai salah satu UMKM yang bergerak di industri makanan dan minuman, mitra dalam kegiatan PKM ini adalah Renafa Food, UMKM yang memproduksi minuman dalam kemasan (ready-to-drink). Renafa Food berdiri pada 21 Desember 2019. Ide awal pendirian UMKM ini karena pemilik Renafa Food memiliki kecintaan pada minuman kopi dan melihat adanya animo masyarakat yang semakin meningkat pada aneka macam olahan kopi dalam bentuk minuman siap saji. Berangkat dari kondisi ini, Renafa Food kemudian meluncurkan KOPINÉ Coffelatte. 
Seiring dengan berjalannya usaha, Renafa Food kemudian mengembangkan produk minuman sehat, C-REFEEL LEMONADE. Minuman ini merupakan minuman yang diolah dari sari jeruk lemon dan madu, yang memiliki khasiat kesehatan selain menjadi minuman pelega dahaga. Renafa Food memiliki visi untuk mengembangkan hobi menjadi peluang usaha yang mampu meningkatkan kesejahteraan masyarakat sekitar. UMKM ini memiliki misi untuk terus menghadirkan inovasi produk makanan dan minuman yang sehat, nikmat dan menyehatkan. Produk KOPINÉ Coffelatte dan C-REFEEL LEMONADE dapat dilihat pada Gambar 1.

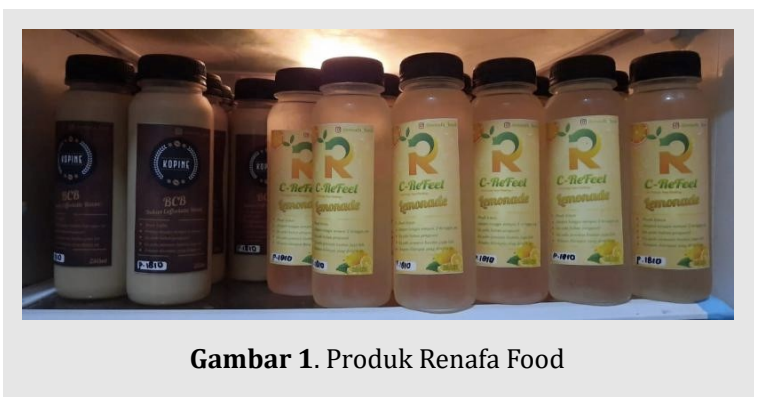

Penjualan produk Renafa Food dilakukan berdasarkan pesanan. Hal ini dikarenakan produk KOPINÉ Coffelatte dan C-REFEEL LEMONADE tidak mengandung bahan pengawet sehingga ketahanannya terbatas. Untuk memperluas segmen pasar, Renafa Food juga menjual kopi bubuk dan biji kopi dalam kemasan. Kopi disimpan dalam kemasan vacuum dan siap diseduh oleh konsumen saat ingin menikmati kopi asli dari berbagai daerah di Indonesia. produk kopi dan biji kopi ini mudah disimpan dan penjualannya dapat menjangkau daerah yang luas karena dapat dikirim melalui jasa pengiriman. Produk ini sebenarnya membuka harapan baru bagi Renafa Food untuk bisa tetap menjalankan bisnisnya secara luas di masa pandemi ini. Namun demikian, karena produk relatif masih baru diperkenalkan, belum banyak konsumen yang mengenal dan membeli produk ini.

Selama ini pemasaran produk KOPINÉ Coffelatte dan C-REFEEL LEMONADE dilakukan melalui promosi di media sosial, Instagram, mouth to mouth, dan pameran. Namun sejak masa pandemi COVID-19 pemasaran produk terkendala karena penjualan terbesar biasanya diperoleh saat pameran. Situasi pandemi yang membatasi berbagai kegiatan di tempat umum membuat Renafa Food tidak dapat mengandalkan penjualan dari pameran. Penjualan produk melalui akun media sosial relatif masih belum optimal karena UMKM ini memiliki sejumlah keterbatasan. Tim PKM berusaha menggali permasalahan yang dihadapi oleh Renafa Food dengan berdiskusi bersama Bapak Fajar selaku pemilik Renafa Food.

Sejak diberlakukannya PSBB di bulan Maret 2020, penjualan Renafa Food mengalami penurunan yang drastis, bahkan sejak akhir April 2020 hingga saat proposal ini disusun, pembelian tiap bulan sangatlah minim. Hal ini disebabkan karena Renafa Food tidak bisa mengikuti pameran-pameran yang menjadi sumber utama penghasilan akibat adanya pembatasan aktivitas penjualan secara fisik. Meskipun telah memiliki akun Instagram yang semestinya bisa digunakan untuk mempromosikan produknya secara online, namun hingga saat ini belum bisa berjalan secara optimal karena berbagai kendala.

Berdasarkan diskusi yang dilakukan melalui telepon oleh tim PKM Universitas Tarumanagara dengan Bapak Fajar terkait dengan permasalahan yang dialami oleh Renafa Food, kami menemukan beberapa poin penting terkait keberlangsungan bisnis ini di masa pandemi Covid-19 maupun masa Normal Baru nantinya. Berikut ini adalah beberapa poin penting yang dapat disimpulkan saat menggali permasalahan Renafa Food, maka tim PKM Universitas Tarumanagara mengusulkan tema Penyusunan/Penguatan Pemasaran dengan Komunikasi Pemasaran. Secara garis besar, masalah utama Renafa Food adalah sebagai berikut:

1. Minimnya transaksi penjualan produk sejak akhir bulan April 2020. 
2. Produksi berhenti karena tidak ada pemasukan bisnis.

3. Kurangnya kompetensi untuk menjalankan bisnis di platform digital/online.

4. Produk yang dihasilkan saat ini tidak dapat bertahan lama karena tidak mengandung pengawet.

5. Belum memiliki strategi pemasaran digital.

6. Kualitas kemasan yang kurang optimal jika akan dipromosikan secara online dan dijual di platform online.

Tim bersama pemilik Renafa Food kemudian menyepakati bahwa terdapat 2 persoalan prioritas yang perlu diselesaikan, yakni aspek manajerial dan aspek teknologi pemasaran/ distribusi. Pada bagan yang ditampilkan di Gambar 2 dapat dilihat kronologi penentuan prioritas permasalahan mitra sesuai dengan kondisi riil yang dihadapi oleh Renafa Food dan analisis lingkungan bisnis yang eksis saat ini.

\section{ASPEK MANAJERIAL}

Salah satu daya tarik yang dimiliki oleh produk yang sukses di pasar saat ini adalah kemasan yang tepat dan menarik. Kita bisa melihat bahwa di media sosial maupun di berbagai platform belanja online produk dengan kemasan menarik dipersepsikan memiliki kualitas yang lebih baik. Oleh sebab itu, jika Renafa Food ingin mendapatkan penilaian yang baik di mata konsumen saat menjalankan promosi digital, maka kemasan produk yang dijual juga perlu diperhatikan.

\section{ASPEK TEKNOLOGI}

Tim PKM membantu mengembangkan strategi pemasaran digital yang dapat diimplementasikan mitra dalam memasarkan produknya di platform digital, serta memudahkan calon konsumennya serta melakukan transaksi jual beli secara online.

\section{METODE}

Berdasarkan analisis permasalahan mitra yang dilakukan pada bagian terdahulu, tim PKM menawarkan solusi yang berfokus pada 2 aspek utama, yaitu aspek manajerial dan aspek teknologi pemasaran/distribusi. Untuk dapat menghasilkan solusi ini maka tim PKM menyusun rencana sebagaimana ditampilkan pada Gambar 3.

Kompleksitas dalam konteks industri dan lingkungan yang dihadapi UKM dalam ekonomi berkembang menantang strategi inovasi dan daya saing internasional UKM Su \& Ren (2014). Pembuat kebijakan, manajer, dan peneliti perlu berkolaborasi dalam upaya meningkatkan lingkungan bisnis untuk pertumbuhan UKM. Dalam upaya inilah maka peran akademisi dalam melakukan transfer teknologi pada mitra UKM sangat diperlukan. Transfer teknologi sesuai bidang ilmu akademisi dan berdasarkan hasil riset yang telah proven dapat membantu UKM untuk terus berkembang dan semakin maju. Kegiatan PKM yang dilakukan oleh Istiqomah et al. (2020). dalam upaya meningkatkan kinerja bisnis melalui strategi pemasaran berbasis online pada UKM produk camilan tradisional menjadi salah satu contoh bentuk kontribusi akademisi dalam membantu pengembangan bisnis UKM.

Tim PKM melakukan kegiatan pengabdian kepada masyarakat untuk UMKM/IKM yang bergerak di bidang industri makanan dan minuman siap saji, yakni Renafa Food, sebagai

Gambar 2. Identifikasi Permasalahan Mitra

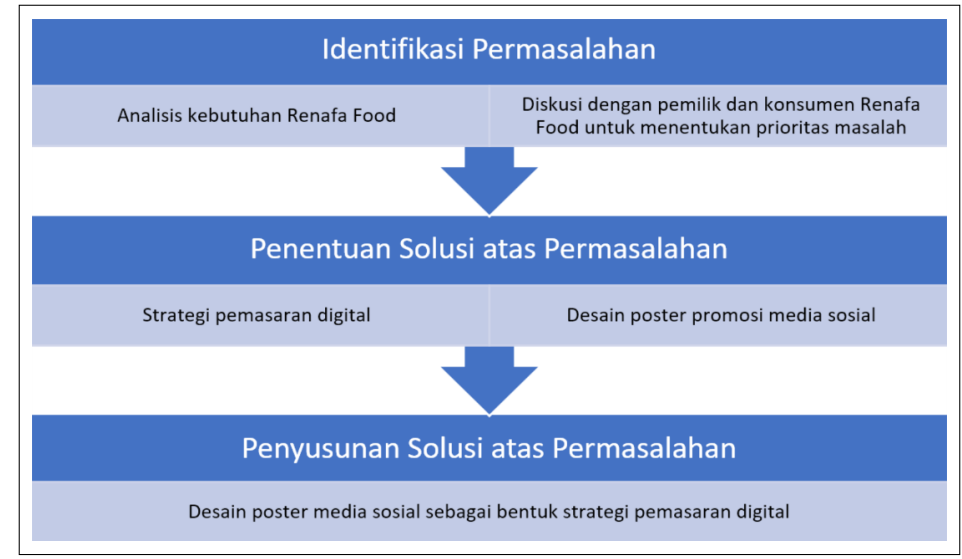

Gambar 3. Tahapan Pelaksanaan PKM 
upaya untuk meningkatkan strategi pemasaran digital berkelanjutan untuk IKM Renafa Food. Luaran yang ditargetkan dari kegiatan ini adalah strategi pemasaran digital serta TTG yang dapat dimanfaatkan oleh Renafa Food berupa poster digital.

\section{HASIL DAN PEMBAHASAN}

Kegiatan berlangsung secara bertahap sejak bulan Juni hingga Oktober 2021. Pada tahap identifikasi permasalahan, disepakati bahwa permasalahan utama yang ingin dipecahkan bagi mitra adalah perlunya alat promosi pemasaran digital. Terdapat dua produk Renafa Food yang diprioritaskan untuk dipromosikan di media sosial, yakni Kopine dan C-Refeel. Pesan yang ingin dikedepankan dari kedua produk ini adalah bahwa Kopine dan C-Refeel adalah minuman yang diproduksi secara homemade dan menggunakan bahan alami tanpa mengandung bahan pengawet. Sesuai dengan pesan tersebut, tim PKM mengembangkan desain poster digital yang dapat digunakan untuk mempromosikan Kopine dan C-Refeel di media sosial. Poster yang dihasilkan dapat dilihat pada Gambar 4.

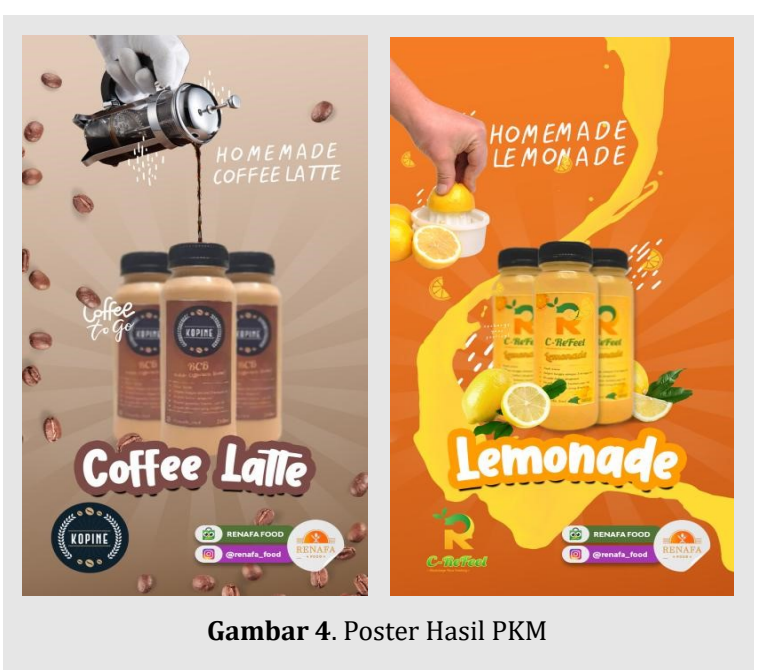

Desain poster digital dibuat sesuai dengan citra yang ingin ditampilkan oleh IKM Renafa Food atas produk Kopine dan Lemonade. Warna yang mendominasi pada poster Kopine adalah warna coklat dan gradasi warna coklat yang menyerupai warna minuman coffee latte Kopine. Adapun warna untuk poster C-Refeel merupakan kombinasi warna kuning dan oranye yang merepresentasikan warna minuman yang dihasilkan dari lemon segar dan madu. Informasi penting yang ditampilkan dalam poster meliputi nama merek, nama produsen, serta informasi mengenai akun di market place digital Tokopedia dan media sosial Instagram. Kegiatan PKM yang menghasilkan alat promosi bagi UMKM juga dilakukan oleh Ekawati et al. (2020) pada UKM ritel daerah Tangerang. Selain itu, Muthohir (2019) juga melakukan PKM untuk mempromosikan UKM di Kendal.

\section{KESIMPULAN DAN SARAN}

Kegiatan PKM ini bertujuan untuk mengembangkan strategi pemasaran digital bagi IKM Renafa Food. Hasil kegiatan PKM berupa poster digital yang dapat digunakan oleh IKM Renafa Food untuk mempromosikan produknya di media sosial. Secara garis besar, kegiatan PKM ini memberikan manfaat positif yang dapat dirasakan langsung oleh mitra, karena hasil kegiatan ini berupa produk yang mampu mendukung strategi pemasaran digital mitra. Dalam era digital, keberadaan alat promosi digital menjadi satu hal yang wajib dimiliki oleh UMKM sebagai upaya menjangkau konsumen secara lebih luas.

Di masa mendatang, kegiatan PKM serupa dapat diselenggarakan bagi UMKM yang belum memiliki alat promosi digital. Sebagaimana pemerintah mendorong UMKM untuk go digital sejak tahun 2020 lalu. Kegiatan PKM yang melibatkan dosen serta mahasiswa dapat diarahkan untuk membantu UMKM mempersiapkan pemasaran digital untuk produknya. 


\section{R E F E R E N C E}

Ekawati, S, Hidayah, N, dan Purwanto, P. (2020) Implementasi strategi keunggulan bersaing dan pendampingan redesain kemasan dalam meningkatkan penjualan pada UKM ritel di Tangerang.

Fauzia, M dan Erlangga, D. (2020) Dampak Covid-19, BPS: 8 dari 10 Perusahaan Alami Penurunan Pendapatan, Kompas, 7 Oktober 2020, diakses dari

https://money.kompas.com/read/2020/10/07/170700926/dampak-covid-19-bps--8-dari-10perusahaan-alami-penurunan-pendapatan-

Hidayat, A dan Hidayat, K. (2020) Pertumbuhan industri makanan dan minuman terhambat selama pandemi corona. Kontan, Senin, 21 September 2021, diakses dari https://industri.kontan.co.id/ news/pertumbuhan-industri-makanan-dan-minuman-terhambat-selama-pandemi-corona

Istiqomah, S, Ajaryanti, Y.F., dan Dewi, A.S. (2020) Peningkatan kinerja bisnis melalui strategi pemasaran berbasis online pada UKM produk camilan tradisional. Diseminasi: Jurnal Pengabdian kepada Masyarakat, Vo. 2 (1), pp 5-18.

Muthohir, M. (2019) Perancangan Media Promosi Produk Unggulan UKM Kendal Berbasis Web dengan Metode R\&D. JURNAL ILMIAH KOMPUTER GRAFIS, Vol.12, No.2, pp. 13-20).

Siregar, H. dan Tambun, L.T., (2019) Ini Lima Program Prioritas Jokowi Periode Mendatang. Beritasatu.com Minggu, 20 Oktober, diakses dari https://www.beritasatu.com/asnie-ovier/politik/580922/inilima-program-prioritas-jokowi-periode-mendatang

$\mathrm{Su}$, P. and Ren, S. (2014), "Sustaining Competitiveness in the Economic Recession: Exploration and Exploitation in Two Small- and Medium-Sized Enterprises in a Developing Economy", Exploration and Exploitation in Early Stage Ventures and SMEs (Technology, Innovation, Entrepreneurship and Competitive Strategy, Vol. 14), Emerald Group Publishing Limited, pp. 237-262. https://doi.org/ 10.1108/S1479-067X20140000014007. 